\title{
ARTICLE
}

Acute myeloid leukemia

\section{Diagnostic and therapeutic pitfalls in NPM1-mutated AML: notes from the field}

\author{
Brunangelo Falini $\mathbb{D}^{1} \cdot$ Sofia Sciabolacci ${ }^{1} \cdot$ Lorenza Falini $^{1} \cdot$ Lorenzo Brunetti $^{1} \cdot$ Maria Paola Martelli $\mathbb{C}^{1}$
}

Received: 17 December 2020 / Revised: 21 February 2021 / Accepted: 9 March 2021 / Published online: 20 April 2021

(c) The Author(s) 2021. This article is published with open access

\begin{abstract}
Mutations of Nucleophosmin (NPMI) are the most common genetic abnormalities in adult acute myeloid leukaemia (AML), accounting for about $30 \%$ of cases. NPM1-mutated AML has been recognized as distinct entity in the 2017 World Health Organization (WHO) classification of lympho-haematopoietic neoplasms. WHO criteria allow recognition of this leukaemia entity and its distinction from AML with myelodysplasia-related changes, AML with BCR-ABL1 rearrangement and AML with RUNX1 mutations. Nevertheless, controversial issues include the percentage of blasts required for the diagnosis of NPM1-mutated AML and whether cases of NPM1-mutated myelodysplasia and chronic myelomonocytic leukaemia do exist. Evaluation of NPMI and FLT3 status represents a major pillar of the European LeukemiaNet (ELN) genetic-based risk stratification model. Moreover, NPM1 mutations are particularly suitable for assessing measurable residual disease (MRD) since they are frequent, stable at relapse and do not drive clonal haematopoiesis. Ideally, combining monitoring of MRD with the ELN prognostication model can help to guide therapeutic decisions. Here, we provide examples of instructive cases of NPM1-mutated AML, in order to provide criteria for the appropriate diagnosis and therapy of this frequent leukaemia entity.
\end{abstract}

\section{Introduction}

The nucleophosmin (NPMI) gene encodes for a multifunctional nucleolar protein with shuttling and chaperone properties [1, 2]. In 2005, we discovered that NPMI was mutated (often in association with FLT3) in about onethird of AML (mostly with normal cytogenetics) and that the NPM1 mutant protein was delocalized in the cytoplasm of leukaemic cells [3]. We subsequently proposed that NPM1-mutated AML represented a disease with distinctive clinical, pathological and molecular features [4] and promoted this concept within the Clinical Advisory Committees of World Health Organization (WHO). This eventually led to include NPM1-mutated AML as a new entity in the 2017 WHO classification of lympho-haematopoietic tumors $[1,5]$.

Brunangelo Falini

brunangelo.falini@unipg.it

1 Institute of Haematology, Centro Ricerche Emato-Oncologiche (CREO), Ospedale S. Maria della Misericordia, University of Perugia, Perugia, Italy
Clinical management of AML patients, including those with NPM1-mutated AML, is based upon the European LeukemiaNet (ELN) genetic-based risk stratification [6, 7]. NPM1-mutated AML without FLT3-ITD or with FLT3-ITD low allelic ratio $\left(<0.5 ; F L T 3-\right.$ ITD $\left.^{\text {low }}\right)$ belongs to the ELN favourable risk category whilst $N P M 1$-mutated AML with FLT3-ITD high allelic ratio $\left(\geq 0.5 ;\right.$ FLT3-ITD $\left.{ }^{\text {high }}\right)$ falls into the intermediate risk group [6]. However, NPM1-mutated AML may carry a large variety of concomitant mutations that may influence its clinical course and prognosis $[8,9]$. Thus, risk stratification of NPMI-mutated AML is an evolving area that in the future is expected to expand, including genotypes other than those currently recognized by the ELN. A recent study also points to the importance of race in risk stratification based on genomics [10].

Assessment of measurable residual disease (MRD) by real time quantitative polymerase chain reaction (RT-qPCR) for NPM1 mutant transcripts [11] can be combined with the ELN risk stratification to inform therapeutic decisions, e.g. helping to select patients who may benefit from allogeneic haematopoietic stem cell transplantation (allo-HSCT) [7]. NPM1 mutations are an ideal target for monitoring MRD since they are AML specific [12], common [3], stable and do not drive clonal haematopoiesis [13]. Moreover, NPMI 
mutant transcripts are expressed at high levels, allowing sensitivity up to $1: 10^{5}-1: 10^{6}$.

Despite most patients achieving MRD-negativity may still have up to $10^{7}$ residual leukaemic cells, they do not relapse, suggesting that the host immune system may control or eradicate the residual disease. Interestingly, $\mathrm{T}$ lymphocytes reactive against HLA-presented NPM1 mutant neoantigens were demonstrated in patients [14]. Conversely, about $30 \%$ of MRD-negative cases relapse [9], probably because their immune system is unable to clear the residual leukaemic cells, especially when FLT3-ITD (imparting a high proliferative index) is present.

Whatever is the mechanism of MRD eradication, achieving MRD negativity in PB [9] or BM [15] or a marked drop of MRD in BM [16, 17] or in PB [18] is predictive of low risk of leukaemia relapse and good survival. Pre-allotransplant monitoring of MRD is also important for predicting outcome, since MRD-positivity in this setting is associated with poor outcome [19-21]. In fact, although allo-HSCT is effective in eradicating MRD, posttransplant MRD negativity is more durable in patients who are MRD-negative before allo-HSCT [22]. Nevertheless, myeloablative allo-HSCT [20] still performs better than standard CHT [18, 23].

Nearly 50\% of MRD-positive patients with $<1000-2000$ NPM1 mutant transcripts copies $/ 10^{5} A B L[24]$ at the end of CHT achieve MRD negativity spontaneously or retain stable low-level expression without relapsing at a minimum follow-up of 8 months [25]. Patients with both FLT3-ITD and $<4 \log$ reduction in NPMI transcript levels at the end of CHT are at high risk of disease progression and should be considered for pre-emptive treatment [25].

In the everyday clinical practice, haematologists involved in management of AML patients have sometimes to face with diagnostically complex cases and difficult therapeutic choices. Here, we present 6 challenging NPM1mutated AML cases, in order to provide criteria for the appropriate diagnosis and therapy of this common leukaemia entity.

\section{Case 1: adult young patient with NPM1- mutated AML, multilineage dysplasia and clonal evolution of FLT3-ITD}

A 58-year-old woman presented with urinary tract infection. The complete blood count (CBC) showed: white blood cells (WBC) $12.8 \times 10^{9} / \mathrm{L}$, haemoglobin $(\mathrm{Hb}) 9.5 \mathrm{~g} / \mathrm{dL}$ and platelets $144 \times 10^{9} / \mathrm{L}$. The bone marrow $(\mathrm{BM})$ showed AML with multilineage dysplasia (MLD). NPM1 mutation A and FLT3 wild-type were detected. The BM karyotype was normal. She was treated with a ' $7+3$ ' regimen, achieving a complete remission $(\mathrm{CR})$ and $2.7 \mathrm{log}$ reduction of NPMI

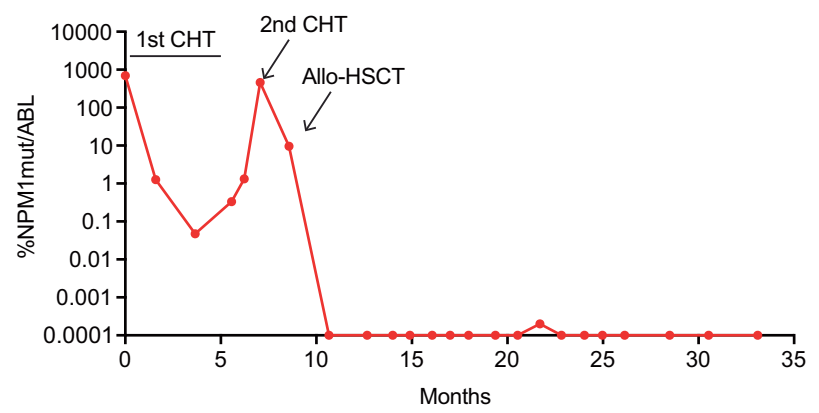

Fig. 1 NPM1 MRD monitoring by RT-qPCR in case 1 . Monitoring of $N P M 1$ mut transcripts during therapy and follow-up (see text). $0.0001 \%$ NPM1mut/ABL is equivalent to MRD negativity. 1st CHT, first line chemotherapy; 2nd CHT, salvage chemotherapy; allo-HSCT, allogeneic haematopoietic stem cell transplant.

mutant transcripts at RT-qPCR (Fig. 1). The patient then received two idarubicin/cytarabine-based consolidation cycles. In the following months, we observed a progressive increase of NPM1 MRD in the BM (Fig. 1) that was rapidly followed by haematological relapse (15\% blasts). A small FLT3-ITD subclone $(0.5 \%)$ had also appeared. She received a combination of fludarabine, cytarabine, idarubicin and etoposide that led to $\mathrm{CR}$ and 1.7-log reduction of NPM1 transcripts (Fig. 1). Allo-HSCT from an haploidentical donor was performed and she is now in molecular CR, almost 2 years after allotransplant (Fig. 1).

\section{Questions and recommendations}

Our patient showed AML with MLD (i.e. dysplasia in at least 50\% of cells, in at least two BM cell lines [5]) and expression of cytoplasmic NPM1 in different haematopoietic cell lineages (Fig. 2A, B). MLD is one of the diagnostic criteria defining AML with myelodysplasia related changes (AML-MRC) but, according to WHO classification, when it coexists with NPMI mutation, the genetic lesion supersedes morphology and the case should be diagnosed as NPMI-mutated AML [5, 7, 26]. Conversely, a previous history of myelodysplastic syndrome (MDS) or MRC-related cytogenetic abnormalities, even in the presence of NPM1 mutation, are diagnostic of AMLMRC [5]. Thus, our patient was diagnosed as NPM1mutated AML since only MLD but no history of MDS or MRC-related cytogenetic abnormalities were documented.

MLD also helps defining the cell of origin of NPM1mutated AML. Studies in mice suggest that NPM1-mutated AML may derive from a granulocytic-monocytic progenitor (GMP) [27]. We propose it may also originate from either a common myeloid progenitor (CMP) or a haematopoietic stem cell (HSC) (Fig. 2C), for the following reasons: (i) Erythroid and megakaryocytic cell lineages frequently show cytoplasmic NPM1 (Fig. 2A, B) or mutations in 
Fig. 2 AML with multilineage dysplasia and cell of origin of NPM1-mutated AML. A Multilineage involvement is documented by the presence of myeloid blasts (single arrow) expressing cytoplasmic NPM1 (blue) and immature erythroid cells (double arrows) expressing cytoplasmic NPM1 (blue) and surface glycophorin (brown) (double staining for NPM1/ immune-alkaline phosphatase APAAP technique and glycophorin/

immunoperoxidase, $x 400$ ). B Another area of BM biopsy showing cytoplasmic NPM1 in dysplastic megakaryocytes (arrow) and myeloid cells (APAAP immunostaining; $\mathrm{x} 400)$ C Cartoon depicting the putative cell of origin of NPM1mutated AML. Lighting bolts indicate the suggested putative cells of origin.
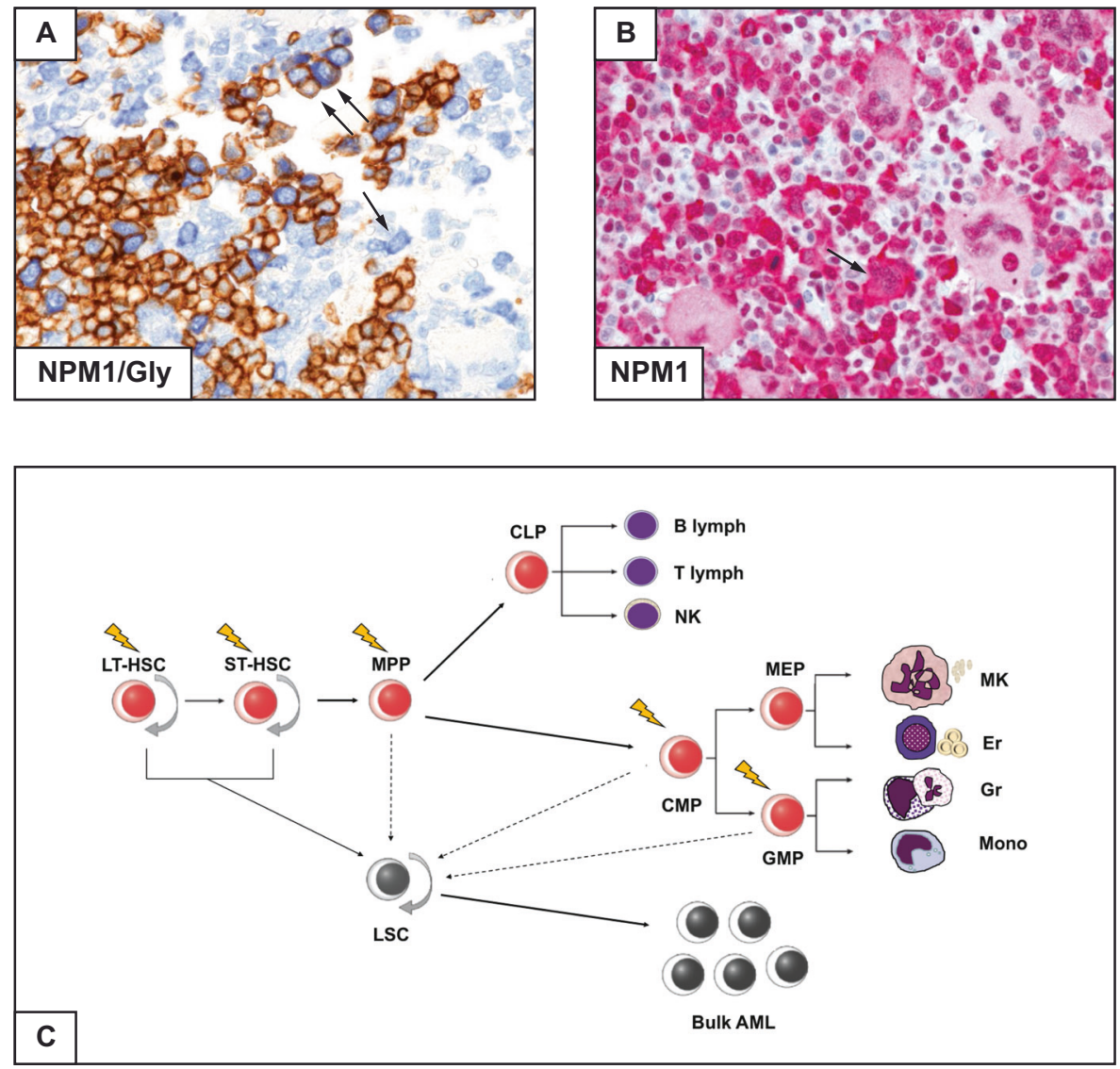

microdissected cells [28]; (ii) Precursors carrying NPMI mutations with the immunophenotype of leukaemic stem cells (CD34 + /CD38-/CD123 + /CD33 + /CD90-) are present in BM of NPMI-mutated AML patients [29]; and (iii) Human NPM1-mutated CD34 + AML cells transplanted into NSG mice generate an AML recapitulating the original patient's disease, with monocytic differentiation and loss of CD34 [29].

Because our patient belonged to the ELN favorable risk category (NPM1-mutated without FLT3-ITD) [6], she received induction plus consolidation without allo-HSCT. In fact, patients with this genotype have $<40 \%$ cumulative risk of relapse and high probability to achieve a second CR and to be salvaged by allo-HSCT. Allo-HSCT in first CR (CR1) has been proposed for patients $<50$ years, with low transplant-related risk and HLA-identical donor [30], but this option remains investigational [7]. Thus, we only administered consolidation CHT.

MRD monitoring documented an early molecular relapse [24] shortly followed by haematological relapse. The molecular relapse may have been heralded by the MRD suboptimal reduction after two cycles of CHT [9]. This could serve as another reasonable criterion for favoring alloHSCT in CR1 [9] in otherwise favorable risk NPM1- mutated AML according to ELN [6]. Currently, this issue is addressed in a multicenter, MRD-driven study on AML patients with favorable/intermediate-risk sponsored by Gruppo Italiano Malattie EMatologiche dell'Adulto, GIMEMA (NCT04168502). Sequential monitoring for MRD may allow pre-emptive intervention before haematological relapse [31-33].

The emergence of a small FLT3-ITD subclone $(0.5 \%)$ at relapse suggests clonal evolution towards a more aggressive AML. FLT3-ITD is an unstable mutation that may be lost (if present at diagnosis) or acquired at relapse. Interestingly, 4/ 6 NPM1-mutated AML patients with FLT3 wild-type at diagnosis who relapsed with FLT3-ITD (according to conventional PCR), harbored very small FLT3-ITD subclones already at diagnosis, when analyzed by a highly sensitive patient-specific RT-qPCR for FLT3-ITD [34].

Therefore, the patient was treated with salvage CHT followed by allo-HSCT. She did not receive an FLT3 inhibitor since it was not approved at that time. Salvage CHT induced a new CR and about 2-log reduction in NPMI transcripts. Although NPMI MRD positivity before alloHSCT has been associated with higher relapse rate [19-21], our patient is still in molecular CR almost 2 years after allotransplant. 
Fig. 3 NPM1/FLT3-D835/ DNMT3A triple-mutated AML with skin involvement. A Skin biopsy showing marked dermal infiltration by leukaemic cells. E indicates the overlying epidermis (Haematoxylin-Eosin, x400). B Leukaemic cells express cytoplasmic NPM1 (single arrow) whilst the cells of the overlying epidermis show nucleus-restricted NPM1 positivity (double arrows) (APAAP immunostaining, $\mathrm{x} 400$ ). E indicates the overlying epidermis. C MRD monitoring by RT-qPCR. $0.0001 \%$

NPM1mut/ABL is equivalent to MRD negativity. CHT + FLT3i, chemotherapy plus midostaurin; AZA + VEN, azacytidine plus venetoclax. Arrows indicate the beginning of each cycle of azacytidine plus venetoclax.
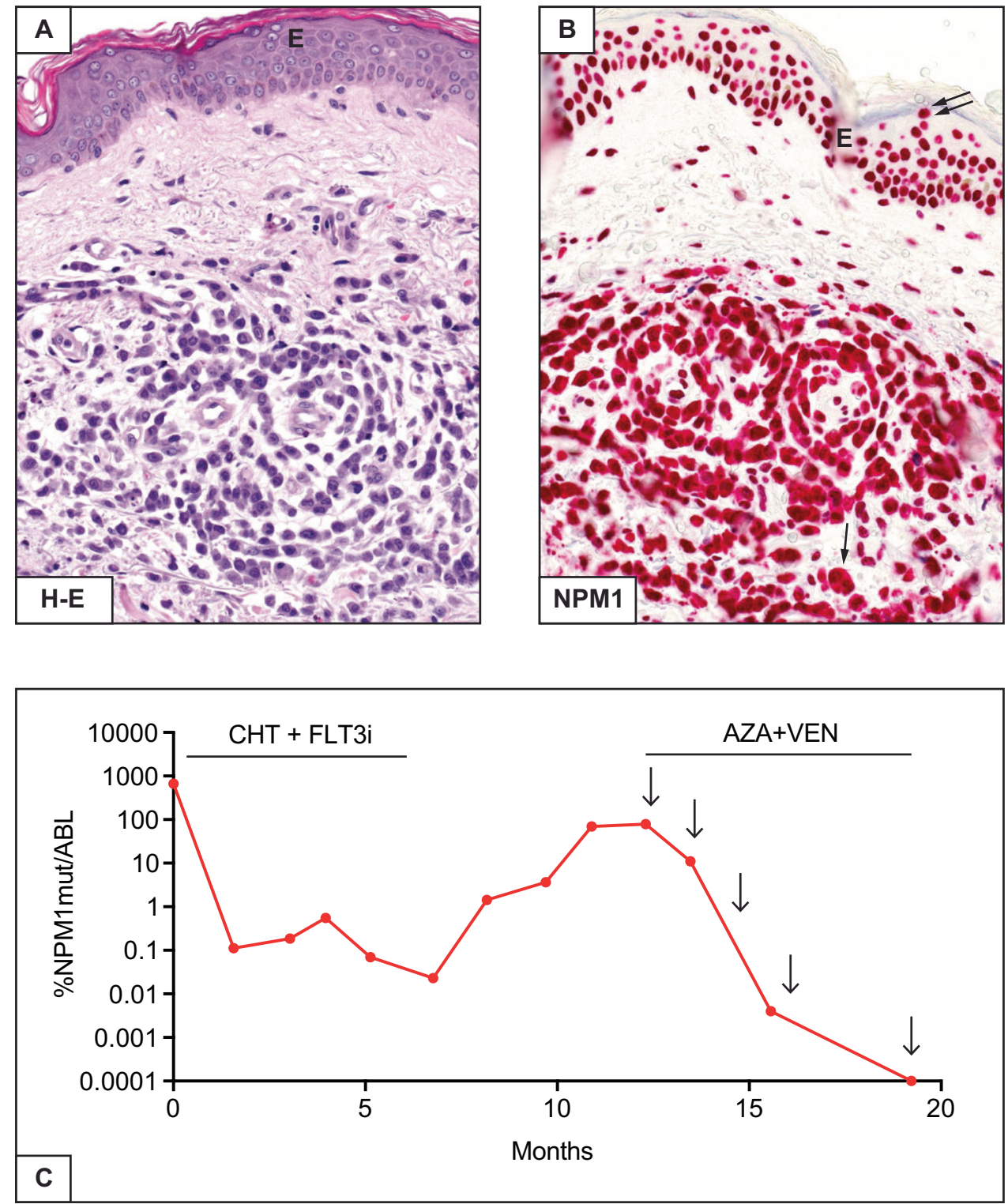

\section{Case 2. Older fit patient with NPM1/FLT3- TKD/DNMT3A triple mutated AML, trisomy 8 and extramedullary disease}

A 72-year-old woman presented because routine examinations revealed WBC $35.8 \times 10^{9} / \mathrm{L}, \mathrm{Hb} 12.6 \mathrm{~g} / \mathrm{dL}$ and platelets $84 \times 10^{9} / \mathrm{L}$. The BM was diffusely infiltrated by myelomonocytic leukaemic cells expressing cytoplasmic NPM1. Mutations of NPM1 (type A), FLT3-D835 and DNMT3A were detected. The BM karyotype revealed a trisomy 8 in about $20 \%$ of metaphases. Multiple lightpurple skin nodules were found on clinical examination and a skin biopsy revealed dermal infiltration by leukaemic cells with cytoplasmic NPM1 (Fig. 3A, B). She received a '7+ 3' regimen plus midostaurin, achieving haematological CR. Disappearance of FLT3-D835 mutation and a 3.8-log reduction of NPMI mutant transcripts were observed (Fig. 3C). The patient received two cytarabine-based consolidation cycles plus a FLT3 inhibitor (midostaurin) achieving a maximum of 4.5-log reduction of NPM1 MRD (Fig. 3C); FLT3-D835 remained negative. In the following months, NPMI MRD in the BM progressively increased (Fig. 3C), the patient remaining in haematological CR. No skin lesions were observed. She received pre-emptive therapy with venetoclax plus the hypomethylating agent (HMA) 5-azacytidine. She is now in molecular CR at the fifth cycle of this combo (Fig. 3C).

\section{Questions and recommendations}

Our patient carried the D835 mutation involving the tyrosine kinase domain (TKD) of FLT3. Accordingly, we 
administered CHT plus midostaurin. The benefit of using this combo for the NPM1-mutated/FLT3-TKD genotype was shown in a recent study [35]. However, the best postremission therapy for these patients (consolidation CHT vs allo-HSCT) remains controversial. In fact, FLT3-TKD mutations have been associated with favorable prognosis in some studies [36-38] but not in others [39, 40]. The NPM1mutated/FLT3-TKD genotype in the RATIFY trial showed a 5-year OS rate of 70\% [35]. Thus, patients receiving CHT plus midostaurin should be probably not allotransplanted in CR1 and we adopt this strategy.

Then, the question raises whether the early molecular relapse in our patient could have been related to the concomitant DNMT3A mutation. In fact, NPM1-mutated AML elderly patients co-mutated for DNMT3A seem to have high risk of relapse even though they achieve good molecular responses post-induction CHT. They should be considered for allo-HSCT or maintenance strategies, even if they belong to the favorable ELN risk group [41].

NPM1-mutated AML co-mutated for FLT3-ITD and DNMT3A was initially recognized to display distinctive microRNA and epigenetic features [42]. The triple-mutated $\mathrm{AML}^{\text {NPM1/FLT3-ITD/DNMT3A }}$ is clinically characterized by high WBC count, monocytic phenotype, absence of multilineage dysplasia, extramedullary involvement, normal karyotype and poor outcome [8, 43, 44]. Our triple-mutated patient carried FLT3-TKD instead of FLT3-ITD. Although it is difficult to make a comparison based upon only one case, she exhibited clinical and biological features similar to those of typical AML ${ }^{\text {NPMI/FLT3-ITD/DNMT3A }}$ and responded poorly to CHT plus midostaurin. The introduction of more powerful FLT3 inhibitors may increase the percentage of triple-mutated patients who may be bridged to alloHSCT. Preclinical studies suggest that triple mutated $\mathrm{AML}^{\text {NPM1/FLT3-ITD/DNMT3A }}$ may be sensitive to venetoclax [45]. Our patient responded to pre-emptive therapy with venetoclax plus HMA, but this observation requires further clinical validation.

Did the trisomy 8 conditioned the suboptimal response to therapy in our case? About $15 \%$ of NPM1-mutated AML exhibit an abnormal karyotype [3], usually characterized by $+8,+4,-\mathrm{Y}, \operatorname{del}(9 \mathrm{q})$ and +21 , monosomy of chromosomes 5 and 7 and complex karyotype being very rare [46]. These aberrations represent secondary late events during the clonal evolution of NPM1-mutated AML [46]. Thus, trisomy 8 (as in our case) has no prognostic impact in NPM1-mutated AML [46]. Adverse-risk aberrations in NPM1-mutated AML include monosomy 7 or 5 or TP53 deletion [47]. However, cases with these genetic abnormalities would fill in the WHO category of AML-MRC.

Skin lesions, as in our patient, have been described in association with NPM1-mutated AML showing monocytic features [48]. Whether skin involvement represents a poor prognostic factor in the context of our patient's genotype remains unknown. In a study including >3,000 AML patients, extramedullary disease did not show an independent prognostic value [49] but mutational landscape was not investigated. Interestingly, our patient relapsed in the BM but not in the skin.

\section{Case 3. Older unfit patient with NPM1- mutated AML without FLT3-ITD presenting during the COVID-19 pandemic}

An asymptomatic 74-year-old woman presented during the COVID-19 pandemic with a routine CBC revealing WBC $2.1 \times 10^{9} / \mathrm{L}, \mathrm{Hb} 7.6 \mathrm{~g} / \mathrm{dL}$ and platelets $109 \times 10^{9} / \mathrm{L}$. BM examination showed infiltration by myelomonocytic leukaemic cells that were negative for CD34, positive for myeloperoxidase and macrophage-restricted CD68, and expressed cytoplasmic NPM1. The NPM1 mutation A was detected whilst FLT3 was wild-type. The BM karyotype was normal. The patient, considered unfit for CHT, received venetoclax plus 5-azacytidine. She achieved MRD-positive $\mathrm{CR}$ after the first cycle and is now in CR MRD-negative after five cycles of this combo.

\section{Questions and recommendations}

What is the best treatment available for our patient? Venetoclax plus HMA or low dose cytarabine (LDAC), induced CR in 70-90\% of NPM1-mutated AML patients $[50,51]$. Similar dramatic responses have been also reported in NPM1-mutated myeloid sarcoma [52, 53]. Thus, the standard therapy for older unfit NPM1-mutated AML patients is now venetoclax plus HMA [7, 50]. CR is frequently achieved after one cycle and the regimen is usually well tolerated, with an early mortality of only 7\% [51]. Nevertheless, patients experience a prolonged drug-related pancytopenia that should be differentiated from refractoriness to therapy by BM evaluation at appropriate time points. Persistent neutropenia may require prolonging intervals between cycles, reducing the duration of venetoclax administration per cycle or using granulocyte colonystimulating factor.

Venetoclax-based regimens have been also recommended as temporary alternative to intensive CHT in older fit NPM1-mutated AML patients during COVID-19 pandemic [54, 55]. MRD assessment may be particularly helpful under these circumstances, although the optimal time points for monitoring need to be established for this combo [56].

Venetoclax plus HMA is also approved by the Italian Drug Agency as frontline therapy for fit AML patients $\geq 75$ years old. In NPM1-mutated AML patients $>65$ years old, 
this combo compared favorably with intensive CHT [57]. However, these results need to be confirmed in randomized prospective studies. We currently treat fit NPMI-mutated AML patients $>60$ but $<75$ years old with standard CHT, although outcome remains poor, independently of FLT3 status (3-year overall survival of 35\%) [58]. Older eligible patients, who achieve complete remission after one or two cycles of CHT, should be offered reduced-intensity conditioning [59] or non-myeloablative [60] allo-HSCT.

\section{Case 4. Pediatric NPM1-mutated AML patient with unusual co-mutations}

A 17-years-old girl presented with fever, cough and abdominal pain. The $\mathrm{CBC}$ showed WBC $1.3 \times 10^{9} / \mathrm{L}, \mathrm{Hb}$ $8.0 \mathrm{~g} / \mathrm{dL}$ and platelet $25 \times 10^{9} / \mathrm{L}$. The BM was diffusely infiltrated by monoblasts positive for macrophage-restricted CD68 and negative for myeloperoxidase and CD34. Next generation sequencing (NGS) of 43 genes detected a previously unnoted NPM1 mutation (see below), a rare FLT3 $\mathrm{N} 841 \mathrm{H}$ mutation and two TET2 mutations. The BM karyotype showed a trisomy 8 in $4 / 25$ metaphases. She received a ' $7+3$ ' induction, achieving CR. NGS after the first consolidation cycle showed disappearance of NPMI mutation but persistence of FLT3-N841H. Parents asked for a consultation since allo-HSCT from the HLA-identical sister was proposed at another Institution.

\section{Questions and recommendations}

NPM1 mutations are much less frequent in the childhood than in adults (about 7\% vs 30\%) [61]. Such a difference could be related to the fact that, in order to occur, NPM1 mutations require a background of clonal haematopoiesis (usually driven by DNMT3A and TET2 mutations) that is a very rare event in children but progressively increases with age [62]. NGS revealed a new NPMI mutation (deletion of two nucleotides and an insertion of four nucleotides at position 864) leading to loss of tryptophans 288 and 290 and the creation of a putative nuclear export signal (NES) at the NPM1 C-terminus, both required for cytoplasmic dislocation of NPM1 [63]. Given the rarity of this NPM1 mutation, NGS and patient-specific RT-qPCR represent the best methods for MRD monitoring in this case.

What is the significance of the accompanying FLT3 and TET2 mutations in our patient? The FLT3-N841H mutation is located in the amino-terminal portion of TKD (activation loop of FLT3) and had previously reported only in one old patient with de novo AML FAB-M5 [64]. FLT3-N841H causes substitution of histidine for asparagine at codon 841 and leads to conformational changes of activation loop similar to substitutions of histidine for isoleucine (N841I) or tyrosine (N841Y) [65] that were previously shown to have transforming properties. Notably, NGS analysis of BM sample in CR after the first consolidation cycle showed disappearance of NPM1 mutation but persistence of FLT3$\mathrm{N} 841 \mathrm{H}$ at $49 \% \mathrm{VAF}$. This finding raised the question whether the mutation was germline or related to clonal haematopoiesis [66]. Presence of FLT3-N841H in patient's hair demonstrated its germline origin. The two mutations of TET2 were missense and most likely not pathogenetically relevant. The lack of impact of trisomy 8 in risk stratification of NPM1-mutated AML patients has been already discussed in case 2.

What is the best post-remission treatment for this young girl? Although the ELN stratification model [6] mainly applies to adult patients age 18-60 years, NPM1 mutations appear to be a prognostic predictor even in children [67]. Because the FLT3-N841H mutation is germline and not functionally relevant, our patient should be assigned to the ELN favorable risk and receive only CHT without FLT3 inhibitors. No allo-HSCT in CR1 is recommended either.

\section{Case 5: AML with NPM1 exon 11 mutation}

A 64-year-old woman presented with fatigue, diarrhea, nausea, dyspnea and fever. CBC showed WBC $43.3 \times 10^{9} /$ $\mathrm{L}, \mathrm{Hb} 3.5 \mathrm{~g} / \mathrm{dL}$ and platelets $67 \times 10^{9} / \mathrm{L}$. The $\mathrm{BM}$ was diffusely infiltrated by leukaemic cells with myelomonocytic (FAB-M4) appearance expressing cytoplasmic NPM1 (Fig. 4A, B) with no mutations at NPM1 exon 12; FLT3 was wild-type and the BM karyotype was normal. She received a ' $7+3$ ' induction regimen, achieving CR. We then administered two consolidation cycles with intermediate dose cytarabine and daunorubicin. She is now in CR, 6 years after the initial diagnosis.

\section{Questions and recommendations}

NPM1 mutations almost exclusively affect exon 12 [68] and all of them cause changes at the C-terminus of NPM1 (mutation of tryptophans and creation of a NES motif) resulting in enhanced nuclear export of NPM1 mutants and their aberrant accumulation in the cytoplasm of AML cells [63]. Very rare mutations involving exons 9 [69], 11 [70] and 5 [71] also lead to cytoplasmic delocalization of mutant NPM1 through a similar molecular mechanism.

Cytoplasmic expression of NPM1 (a surrogate for NPM1 mutations) can be detected by IHC in BM biopsies [3]. In our patient, the discrepancy between IHC (cytoplasmic NPM1) and conventional molecular analysis of exon 12 (absence of NPM1 mutation) prompted us to study the entire NPM1 coding sequence, revealing a mutation at exon 11 (Fig. 4C), similar to the one we previously described [70]. 
Fig. 4 AML with mutation of NPM1, exon 11. A Diffuse BM infiltration by leukaemic cells. Dysplastic megakaryocytes are also present (arrow). B Mononucleated blasts and dysplastic megakaryocytes (arrow) express cytoplasmic NPM1 (APAAP

immunostaining, $\mathrm{x} 400$ ). C Sanger sequencing of exon 11 showing a heterozygous 8 nucleotides insertion leading to a stop codon at amino acid 275. D Schematic representation of the new mutant protein (Mut) compared with the wild-type (WT). Analysis of the new protein sequence predicted a truncated protein $(274$ aa length), with a newly acquired NES motif (VxxxFxxLxIx). Both proteins are recognized by the anti-NPM1, Clone $376 \mathrm{mAb}$ : monoclonal antibody.
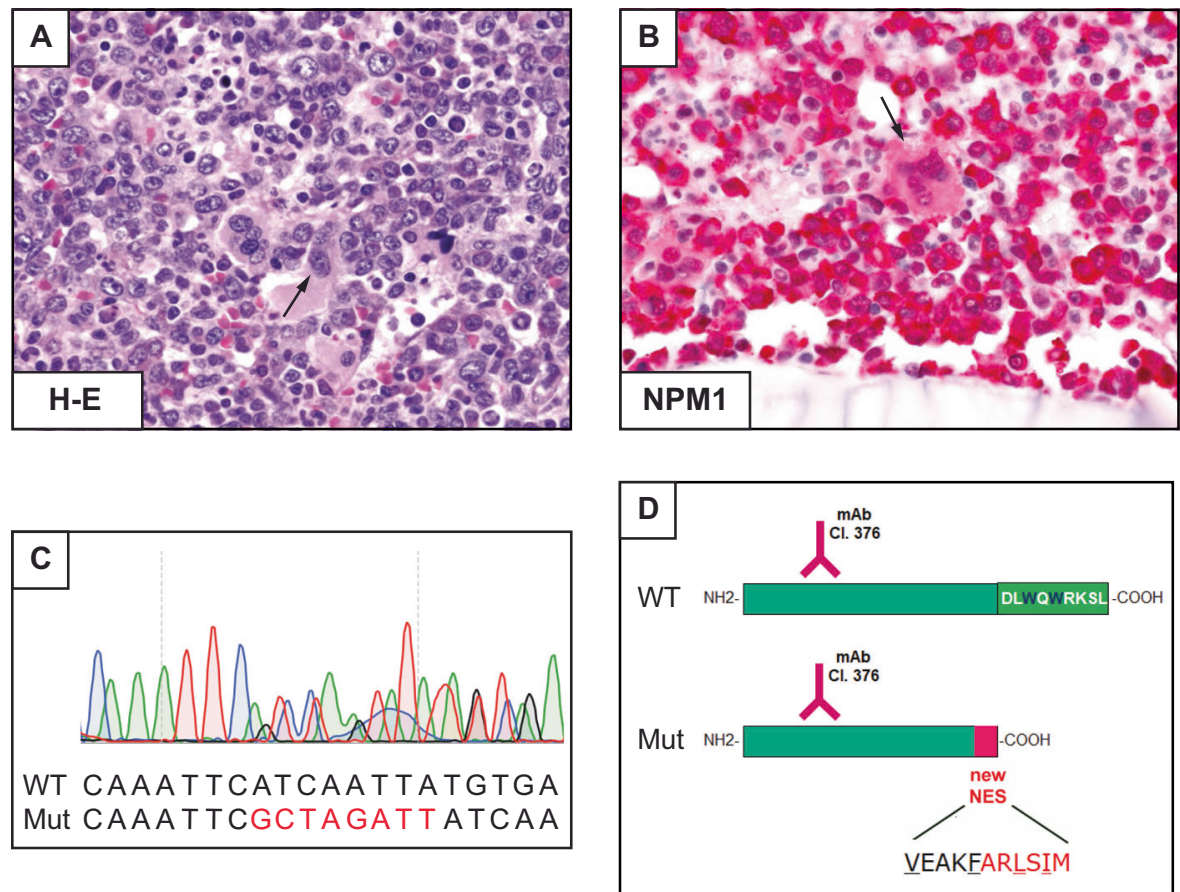

As expected, this mutation caused the loss of the two Cterminal tryptophans and the creation of a NES (Fig. 4D), explaining the abnormal cytoplasmic localization of NPM1.

IHC represents a valuable tool for predicting all NPMI mutations [72]. NGS can also identify all NPM1 mutations but the commercially available panels are designed to recognize mutations at exon 12 only. Thus, they must be adapted for this purpose. Without IHC or NGS, cases like ours would be wrongly assigned to the ELN intermediate risk category (NPMI wild-type without FLT3-ITD) rather than to the favorable risk group (NPM1-mutated without FLT3-ITD). Our patient had good outcome after CHT alone, suggesting that cases with exon 11 mutations may behave similarly to those with exon 12 mutations, but confirmatory studies are needed. MRD monitoring of these very rare $N P M 1$ mutations may require designing a patientspecific RT-qPCR assay [73].

\section{Case 6: NPM1-mutated AML carrying BCR- $A B L 1$}

A 49-year-old man presented with fever, myalgia, haematuria, WBC $98.7 \times 10^{9} / \mathrm{L}, \mathrm{Hb} 9.9 \mathrm{~g} / \mathrm{dL}$ and platelets $14 \times$ $10^{9} / \mathrm{L}$. BM evaluation performed at another Institution was diagnostic of AML with 46,XY,t(9;22)(q34;q11)[9]/47, idem, $+8[7] / 46, \mathrm{XY}[4]$; a $B C R-A B L 1$ rearrangement (p210 fusion) (Fig. 5A) and NPM1 mutation type B were detected (Fig. 5B), whilst FLT3 was wild type. Dasatinib was started at a different institution but discontinued after 2 weeks due to pericardial effusion. He presented at our Institution with WBC $2.3 \times 10^{9} / \mathrm{L}, \mathrm{Hb} 7.8 \mathrm{~g} / \mathrm{dl}$ and platelets $19 \times 10^{9} / \mathrm{L}$. BM biopsy was massively infiltrated by myeloid (FAB-M2) blasts (Fig. 5C) expressing cytoplasmic NPM1 (Fig. 5D), indicating no response to dasatinib. Sequencing $A B L 1$ exons 4-10 showed no mutations. A ' $7+3$ ' regimen induced partial response (10\% residual NPM1 cytoplasmicpositive AML cells) (Fig. 5E, F). He was re-induced with fludarabine, cytarabine and idarubicin, achieving CR whilst fluorescent in situ hybridization (FISH) revealed $0.5 \%$ of nuclei with $B C R-A B L 1$. He underwent allo-HSCT from an HLA-identical sibling and is now in molecular CR for NPM1 and BCR-ABL1, 12 months after the allotransplant.

\section{Questions and recommendations}

NPM1 mutations have been reported in de novo AML with $B C R-A B L 1$ but not in chronic myeloid leukaemia in blastic phase [74-76]. How should this patient be classified? In the 2017 WHO classification [5], NPM1-mutated AML and AML with $B C R-A B L 1$ represent a 'distinct' and a 'provisional' entity, respectively [5]. Therefore, $N P M 1$ mutations supersede $B C R-A B L 1$ and our case should be diagnosed as NPM1-mutated AML, annotating the presence of $B C R$ $A B L 1$ [5]. Notably, leukaemic cells showed CD34 negativity that is more consistent with NPM1-mutated AML [3] than with BCR-ABL1 AML [5]. The relative contribution of the two genetic abnormalities to leukaemogenesis remains to be established. 
Fig. 5 AML with NPMI mutation and $B C R-A B L I$ rearrangement. A G-banding showing a subclone with the following karyotype: $47, \mathrm{XY}, \mathrm{t}$ $(9 ; 22)(\mathrm{q} 34 ; \mathrm{q} 11),+8$ (see the text for the full karyotype). B Sanger trace of NPM1 exon 12, demonstrating mutation B. C Massive BM infiltration by leukaemic cells. $\mathrm{T}$ indicates bone trabecula (BM biopsy, haematoxylin-eosin, x400). D Leukaemic cells exhibit aberrant cytoplasmic expression of NPM1 (BM biopsy, APAAP staining, x400). E BM reevaluation after the first cycle of CHT. Good recovery of normal haematopoietic cells showing nucleus-restricted NPM1 positivity (indicative of NPMI wild-type). A small cluster of residual leukaemic cells with cytoplasmic NPM1 is seen (arrow) (BM biopsy, APAAP immunostaining, $\mathrm{x} 100)$. F Higher magnification of the small cluster of NPM1 cytoplasmic leukaemic cells (arrow) shown in Fig. 4E (BM biopsy, APAAP immunostaining, $x 400$ ).
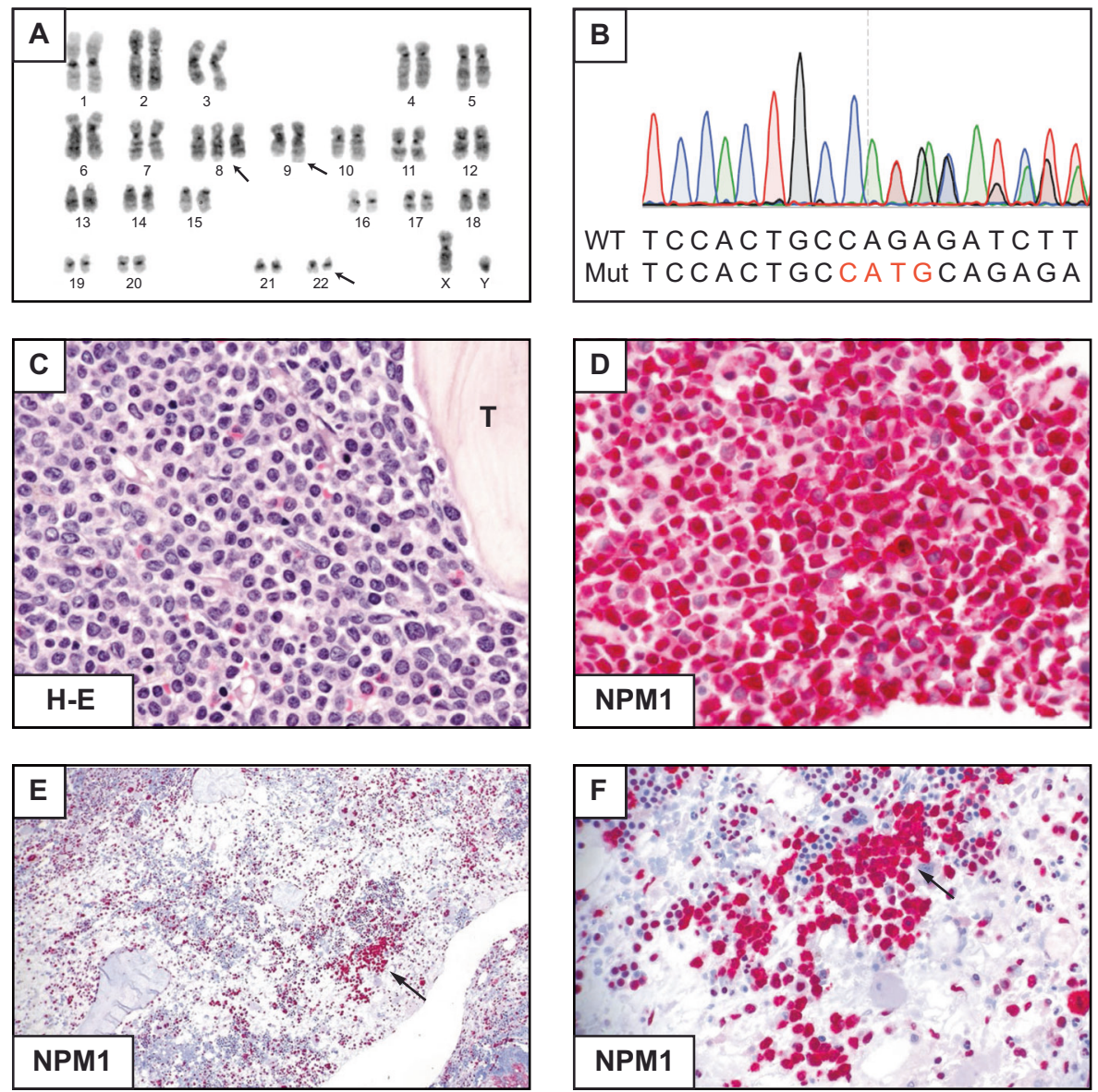

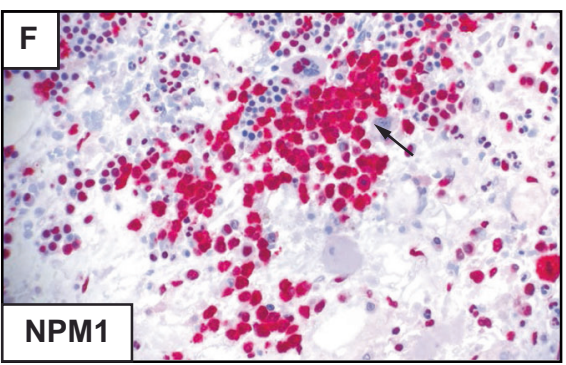

What is the prognostic impact of these genetic alterations? In the 2017 ELN model, AML with $B C R-A B L 1$ is regarded as high-risk disease [77] whilst $N P M 1$-mutated AML without FLT3-ITD has a relatively good outcome [6]. ELN recommendations [6] do not comment on the combination of $N P M 1$ mutations and $B C R-A B L 1$. Interestingly, two patients carrying NPM1 mutation and $B C R-A B L 1$ were alive 36 and 71 months after diagnosis [74], suggesting that they may behave more like a NPM1-mutated AML than as de novo AML with $B C R-A B L 1$. However, further studies are required.

\section{Practical recommendations for the clinical management of NPM1-mutated AML patient}

NPM1-mutated AML should be suspected in a middle-age or older patient who presents with M4-M5 morphology [3], cup-like nuclei [78] or multilineage involvement [26] (case 1 ), a yet relatively preserved number of platelets despite high WBC count and negativity for CD34. Hyperleukocytosis usually associates with a concomitant mutation of FLT3 or RAS. A low WBC count does not exclude NPM1mutated AML since cases with FLT3 wild-type may have this presentation, despite the BM tends to remain not hypocellular [79]. Independently of high WBC count, NPM1 or/and FLT3-ITD mutations may associate with disseminated intravascular coagulation [80]. Extramedullary involvement may occur [7], especially in skin (case 2).

In haematological centers performing BM biopsy at presentation, demonstration by IHC of cytoplasmic NPM1 may serve as surrogate to molecular techniques in case of dry tap or myeloid sarcoma [7] (case 2). Moreover, as discussed in case 5, IHC could predict even rare NPM1 mutations occurring at exons other than 12 and even NPM1containg fusion transcripts [81].

Confirmation of diagnosis requires the identification of NPM1 mutation by Sanger or the more sensitive NGS technique (detecting 1-5\% of mutated cells, depending on the allele coverage). NGS can also identify concomitant driver mutations, even within subclones. Identifying the exact type of NPM1 mutation [11, 82] is critical for settingup the strategy of MRD monitoring (see below).

Once a NPM1 mutation has been recognized, the definitive diagnosis of NPM1-mutated AML requires that other distinct and provisional AML entities of the 2017 WHO classification, such as AML-MRC (case 2), AML with $B C R-A B L 1$ (case 6, Fig. 6) and AML with RUNX1 
Fig. 6 Differential diagnosis of NPM1-mutated AML.

Decisional algorithm

for distinguishing NPM1-

mutated AML from AML with

$B C R-A B L 1$ and AML with

$R U N X 1$ mutations (two

provisional entities of the 2017

WHO classification of

haematopoietic tumors).

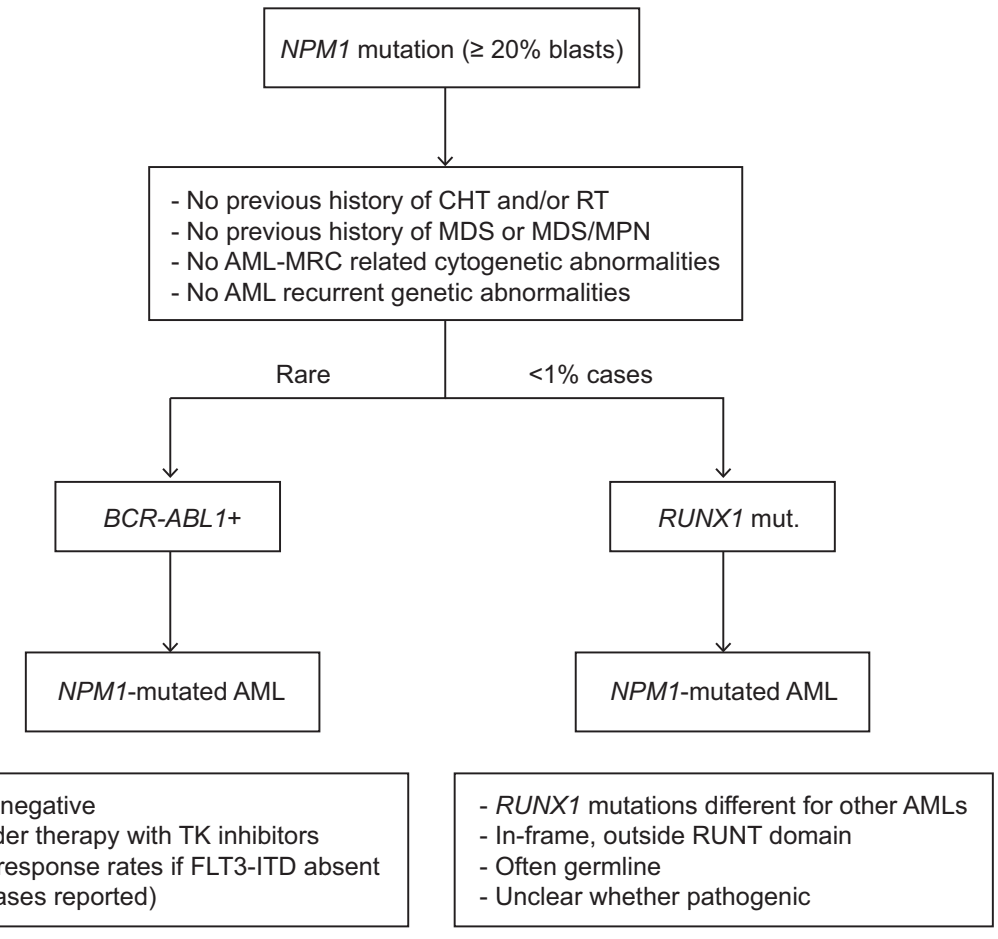

mutations (Fig. 6) are excluded. According to WHO 2017, the diagnosis of NPM1-mutated AML requires $\geq 20 \% \mathrm{BM}$ blasts [5] (Fig. 6). However, the rare cases diagnosed as NPM1-mutated MDS show rapid transformation to AML [83] and respond better to CHT than to HMAs [84], suggesting that NPM1 mutations may define AML irrespective of blast percentage [85]. Similarly, NPM1-mutated chronic myelomonocytic leukaemia (CMML) cases [86, 87] often carry a normal karyotype and tend to evolve rapidly to AML [86], especially those with high NPM1 mutation allelic burden [87]. In our experience, they usually represent NPM1-mutated AML presenting with marked monocytosis.

Once the diagnosis of NPM1-mutated AML has been established, the patient should be assigned to one of the ELN categories, either favorable (if FLT3 is wild-type or low ratio) or intermediate (FLT3-ITD $\left.{ }^{\text {high }}\right)$. Cases co-mutated for NPM1 and FLT3 should be possibly analyzed for $D N M T 3 A$ to exclude the triple mutated genotype, which shows a particularly adverse outcome. As discussed in cases $1,2,3$ and 4, risk stratification is important in guiding frontline (whether to use or not a FLT3 inhibitor) and postremission therapeutic decisions (whether to perform or not allo-HSCT). Patient's age and fitness are other important parameters to be considered for choosing between CHT and venetoclax-based regimens or for deciding whether to perform or not allo-HSCT.

As discussed in cases 1 and 2, MRD monitoring (Fig. 7) during and after completion of CHT $+/$ - allo-HSCT is a critical step in NPM1-mutated AML [24]. In fact, progressive raising of $\mathrm{MRD}$ levels is a reliable predictor of impending haematological relapse [15, 24, 88]. Patients in molecular relapse (as case 2 ) are candidates for pre-emptive therapy [31-33], although it still remains uncertain whether converting pre-transplant MRD positivity into negativity is clinically relevant. Relapse without detectable NPM1 mutation points to a second AML [89-91] (Fig. 7).

\section{Conclusions and future perspectives}

Although the presence of NPMI mutations cannot overcome the prognostic relevance of high-risk cytogenetic abnormalities (e.g. monosomy 7 defining AML-MRC), available data suggest that it probably supersedes the value of blast count. Indeed, the rare cases diagnosed as NPM1mutated MDS or CMML often show features overlapping with AML [83-87]. Therefore, we envision that future issues of the WHO classification will identify NPMI mutations as genetic abnormalities sufficient to diagnose acute myeloid leukaemia regardless of the blast count, joining $\mathrm{t}(8 ; 21)$, inv(16), $\mathrm{t}(16 ; 16)$, and $\mathrm{t}(15 ; 17)$.

Despite great progresses, improving standardization of MRD monitoring and therapy of NPM1-mutated AML remain a medical need. MRD monitoring is usually done by RT-qPCR [11]. However, highly sensitive NGS techniques for monitoring NPM1 MRD have become available [9294]. Digital droplet PCR may be an alternative, even for assessing rare NPM1 mutations [95].

Incorporation of gemtuzumab ozogamicin has been advocated in the frontline treatment of NPM1-mutated 


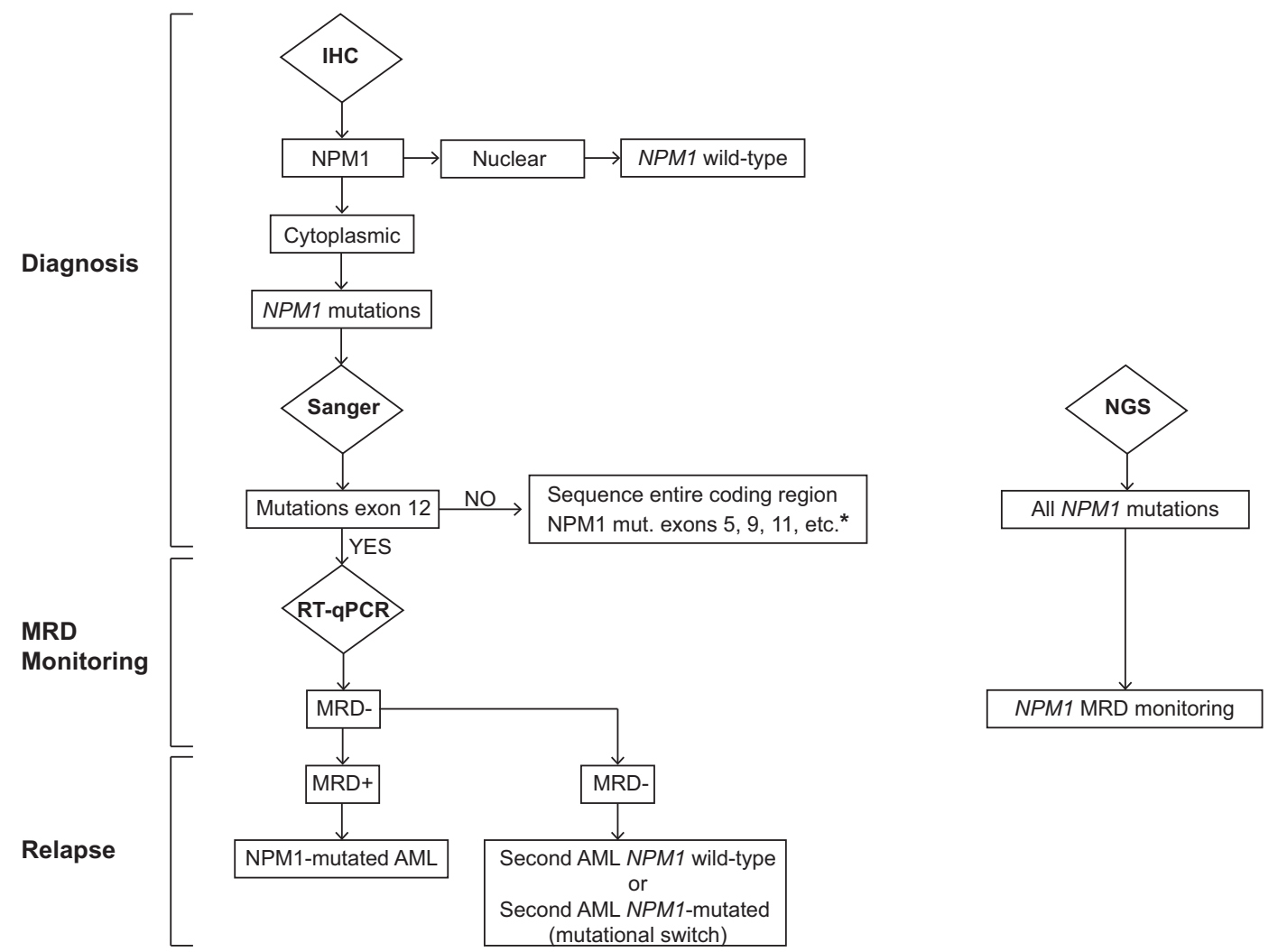

Fig. 7 Decisional algorithm for the molecular diagnosis of NPMImutated AML and monitoring of MRD. Immunohistochemical analysis (IHC) on BM trephine discriminates between AML with nuclear localization of nuclephosmin (predictive of wild-type NPM1 gene), and AML with cytoplasmic staining for NPM1 (predictive of NPM1 mutations). Standard Sanger sequencing of NPM1 exon 12 (involved in almost all cases) allows identification of the specific NPM1 mutations. The discrepancy between IHC (cytoplasmic NPM1) and conventional molecular analysis of exon 12 (absence of NPM1 mutation) should prompt to study the entire NPM1 coding sequence to exclude mutations in other exons. Application of RT-qPCR to monitor

AML [96-98]. Potential of venetoclax plus CHT [99-101] and mechanisms of resistance to venetoclax [102] should be further explored in NPM1-mutated AML. The good outcome of NPMI-mutated AML with FLT3-ITD ${ }^{\text {low }}$ was questioned in recent CHT-based studies [103-105], whilst clearly emerged in trials using CHT plus midostaurin [106]. Thus, the best post-remission therapy for this genotype remains controversial. Translation into clinic of XPO1 [107] and MLL-Menin inhibitors [27, 108], alone or combined with FLT3 inhibitors [109] is warranted. Finally, NPM1 mutant neoantigens complex may be a potential target for immunotherapy [110].

Acknowledgements This work was supported by the Associazione Italiana per la Ricerca sul Cancro (AIRC IG 2019 n. 23604 and AIRC Start-Up 2019 n. 22895), the European Research Council (ERC Advanced Grant 2016 no. 740230 and ERC Consolidator Grant 2016 no. 725725) and the ARC Foundation for Cancer Research (Leopold Griffuel Prize to BF). We thank Dr. Cristina Mecucci
MRD to be performed during CHT and at interval of 3 months for at least 2 years after the end of CHT $+1-$ allo-HSCT. NGS has the potential to identify all NPMI mutations but the commercially available panels should be implemented to include, together with exon 12 , at least exon 11, 9 and 5. *Should the entire coding sequence be wildtype, FISH to exclude very rare NPM1 fusions should be considered. RNA sequencing should be also performed in these cases to identify novel NPM1 translocations. NGS can be used also for MRD monitoring. Relapse with no detectable NPM1 mutation points towards a diagnosis of second AML.

for kindly providing the karyotype of case 6 and Dr. Enrico Tiacci and Dr. Alessandra Venanzi for NGS studies of case 4. We apologize with those whose papers could not be cited owing to space limitation.

Author contributions All authors co-wrote the paper and were involved in the diagnosis or therapy of the described cases. B.F. coordinated the preparation of the paper.

\section{Compliance with ethical standards}

Conflict of interest BF licensed a patent on NPM1 mutants (n. 102004901256449). BF and MPM declare honoraria from Rasna Therapeutics, Inc for scientific advisor activities. MPM also declares consultancy at scientific advisory board for Abbvie, Amgen, Celgene, Janssen, Novartis, Pfizer, Jazz Pharmaceuticals, and honoraria from Amgen, Celgene, Janssen, Novartis. LB declares consultancy at scientific advisory boards for Abbvie.

Publisher's note Springer Nature remains neutral with regard to jurisdictional claims in published maps and institutional affiliations. 
Open Access This article is licensed under a Creative Commons Attribution 4.0 International License, which permits use, sharing, adaptation, distribution and reproduction in any medium or format, as long as you give appropriate credit to the original author(s) and the source, provide a link to the Creative Commons license, and indicate if changes were made. The images or other third party material in this article are included in the article's Creative Commons license, unless indicated otherwise in a credit line to the material. If material is not included in the article's Creative Commons license and your intended use is not permitted by statutory regulation or exceeds the permitted use, you will need to obtain permission directly from the copyright holder. To view a copy of this license, visit http://creativecommons. org/licenses/by/4.0/.

\section{References}

1. Falini B, Brunetti L, Sportoletti P, Martelli MP. NPM1-mutated acute myeloid leukemia: from bench to bedside. Blood. 2020;136(Oct):1707-21.

2. Cela I, Di Matteo A, Federici L. Nucleophosmin in Its Interaction with ligands. Int J Mol Sci. 2020;21(Jul):4885 https://doi. org/10.3390/ijms21144885.

3. Falini B, Mecucci C, Tiacci E, Alcalay M, Rosati R, Pasqualucci $\mathrm{L}$, et al. Cytoplasmic nucleophosmin in acute myelogenous leukemia with a normal karyotype. N. Engl J Med. 2005;352 (Jan):254-66.

4. Falini B, Martelli MP, Bolli N, Sportoletti P, Liso A, Tiacci E, et al. Acute myeloid leukemia with mutated nucleophosmin (NPM1): is it a distinct entity? Blood. 2011;117(Jan):1109-20.

5. Arber DA, Brunning RD, Le Beau MM, Falini B, Vardiman JW, Porwit A, et al. Acute myeloid leukaemia with recurrent genetic abnormalities. In: Swerdlow S et al. editors. WHO Classification of Tumours of Haematopoietic and Lymphoid Tissues. Lyon: International Agency for Research on Cancer (IARC); 2017. p. 130-49.

6. Dohner H, Estey E, Grimwade D, Amadori S, Appelbaum FR, Buchner T, et al. Diagnosis and management of AML in adults: 2017 ELN recommendations from an international expert panel. Blood. 2017;129(Jan):424-47.

7. Falini B, Brunetti L, Martelli MP. How I diagnose and treat NPM1-mutated AML. Blood. 2021;137(Feb):589-99.

8. Papaemmanuil E, Gerstung M, Bullinger L, Gaidzik VI, Paschka $\mathrm{P}$, Roberts ND, et al. Genomic classification and prognosis in acute myeloid leukemia. N. Engl J Med. 2016;374 (Jun):2209-21.

9. Ivey A, Hills RK, Simpson MA, Jovanovic JV, Gilkes A, Grech A, et al. Assessment of minimal residual disease in standard-risk AML. N. Engl J Med. 2016;374(Feb):422-33.

10. Bhatnagar B, Kohlschmidt J, Mrozek K, Zhao Q, Fisher JL, Nicolet D, et al. Poor survival and differentiali impact of genetic features of black patients with acute myeloid leukemia. Cancer Discov. 2021;11(Mar):626-37.

11. Gorello P, Cazzaniga G, Alberti F, Dell'Oro MG, Gottardi E, Specchia G, et al. Quantitative assessment of minimal residual disease in acute myeloid leukemia carrying nucleophosmin (NPM1) gene mutations. Leukemia. 2006;20(Jun):1103-8.

12. Liso A, Bogliolo A, Freschi V, Martelli MP, Pileri SA, Santodirocco $\mathrm{M}$, et al. In human genome, generation of a nuclear export signal through duplication appears unique to nucleophosmin (NPM1) mutations and is restricted to AML. Leukemia. 2008;22(Jun):1285-9.

13. Hasserjian RP, Steensma DP, Graubert TA, Ebert BL. Clonal hematopoiesis and measurable residual disease assessment in acute myeloid leukemia. Blood. 2020 (May); 135: 1729-38.
14. Greiner J, Schneider V, Schmitt M, Gotz M, Dohner K, Wiesneth $\mathrm{M}$, et al. Immune responses against the mutated region of cytoplasmatic NPM1 might contribute to the favorable clinical outcome of AML patients with NPM1 mutations (NPM1(mut)). Blood. 2013;122(Aug):1087-8.

15. Kronke J, Schlenk RF, Jensen KO, Tschurtz F, Corbacioglu A, Gaidzik VI, et al. Monitoring of minimal residual disease in NPM1-mutated acute myeloid leukemia: a study from the German-Austrian acute myeloid leukemia study group. J Clin Oncol. 2011;29(Jul):2709-16.

16. Schnittger S, Kern W, Tschulik C, Weiss T, Dicker F, Falini B, et al. Minimal residual disease levels assessed by NPM1 mutation-specific RQ-PCR provide important prognostic information in AML. Blood. 2009;114(Sep):2220-31.

17. Shayegi N, Kramer M, Bornhauser M, Schaich M, Schetelig J, Platzbecker U, et al. The level of residual disease based on mutant NPM1 is an independent prognostic factor for relapse and survival in AML. Blood. 2013;122(Jul):83-92.

18. Balsat M, Renneville A, Thomas X, de Botton S, Caillot D, Marceau A, et al. Postinduction minimal residual disease predicts outcome and benefit from allogeneic stem cell transplantation in acute myeloid leukemia with NPM1 mutation: a study by the Acute Leukemia French Association Group. J Clin Oncol. 2017;35(Jan):185-93.

19. Kayser S, Benner A, Thiede C, Martens U, Huber J, Stadtherr P, et al. Pretransplant NPM1 MRD levels predict outcome after allogeneic hematopoietic stem cell transplantation in patients with acute myeloid leukemia. Blood Cancer J. 2016;6 (Jul):e449.

20. Bill M, Grimm J, Jentzsch M, Kloss L, Goldmann K, Schulz J, et al. Digital droplet PCR-based absolute quantification of pretransplant NPM1 mutation burden predicts relapse in acute myeloid leukemia patients. Ann Hematol. 2018;97 (Oct):1757-65.

21. Dillon R, Hills R, Freeman S, Potter N, Jovanovic J, Ivey A, et al. Molecular MRD status and outcome after transplantation in NPM1-mutated AML. Blood. 2020;135(Feb):680-8.

22. Stahl M, Derkach A, Famulare C, Cho C, Devlin S, Farnoud N, et al. Molecular predictors and effectiveness of measurable residual disease (MRD) eradication with chemotherapy and allogeneic stem cell transplantation for acute myeloid leukemia. Blood. 2020;136:18-20.

23. Lussana F, Caprioli C, Stefanoni P, Pavoni C, Spinelli O, Buklijas K, et al. Molecular detection of minimal residual disease before allogeneic stem cell transplantation predicts a high incidence of early relapse in adult patients with NPM1 positive acute myeloid leukemia. Cancers (Basel). 2019;11(Sep):1455 https:// doi.org/10.3390/cancers11101455.

24. Schuurhuis GJ, Heuser M, Freeman S, Bene MC, Buccisano F, Cloos J, et al. Minimal/measurable residual disease in AML: a consensus document from the European LeukemiaNet MRD Working Party. Blood. 2018;131(Mar):1275-91.

25. Tiong IS, Dillon R, Ivey A, Kok CH, Kuzich JA, Thiagarajah N, et al. The natural history of NPM1MUT measurable residual disease (MRD) positivity after completion of chemotherapy in acute myeloid leukemia (AML). Blood. 2020;136:25-7.

26. Falini B, Macijewski K, Weiss T, Bacher U, Schnittger S, Kern $\mathrm{W}$, et al. Multilineage dysplasia has no impact on biologic, clinicopathologic, and prognostic features of AML with mutated nucleophosmin (NPM1). Blood. 2010;115(May):3776-86.

27. Uckelmann HJ, Kim SM, Wong EM, Hatton C, Giovinazzo H, Gadrey JY, et al. Therapeutic targeting of preleukemia cells in a mouse model of NPM1 mutant acute myeloid leukemia. Science. 2020;367(Jan):586-90.

28. Pasqualucci L, Liso A, Martelli MP, Bolli N, Pacini R, Tabarrini A, et al. Mutated nucleophosmin detects clonal multilineage 
involvement in acute myeloid leukemia: impact on WHO classification. Blood. 2006;108(Dec):4146-55.

29. Martelli MP, Pettirossi V, Thiede C, Bonifacio E, Mezzasoma F, Cecchini D, et al. CD34+ cells from AML with mutated NPM1 harbor cytoplasmic mutated nucleophosmin and generate leukemia in immunocompromised mice. Blood. 2010;116 (Nov):3907-22.

30. Rollig C, Bornhauser M, Kramer M, Thiede C, Ho AD, Kramer A, et al. Allogeneic stem-cell transplantation in patients with NPM1-mutated acute myeloid leukemia: results from a prospective donor versus no-donor analysis of patients after upfront HLA typing within the SAL-AML 2003 trial. J Clin Oncol. 2015;33(Feb):403-10.

31. Guolo F, Minetto P, Clavio M, Miglino M, Colombo N, Cagnetta A, et al. Longitudinal minimal residual disease (MRD) evaluation in acute myeloid leukaemia with NPM1 mutation: from definition of molecular relapse to MRD-driven salvage approach. Brit J Haematol. 2019;186(Sep):e223-5.

32. Platzbecker U, Middeke JM, Sockel K, Herbst R, Wolf D, Baldus CD, et al. Measurable residual disease-guided treatment with azacitidine to prevent haematological relapse in patients with myelodysplastic syndrome and acute myeloid leukaemia (RELAZA2): an open-label, multicentre, phase 2 trial. Lancet Oncol. 2018;19(Dec):1668-79.

33. Bataller A, Onate G, Diaz-Beya M, Guijarro F, Garrido A, Vives $\mathrm{S}$, et al. Acute myeloid leukemia with NPM1 mutation and favorable European LeukemiaNet category: outcome after preemptive intervention based on measurable residual disease. Brit $\mathbf{J}$ Haematol. 2020;191(Oct):52-61.

34. Ottone T, Zaza S, Divona M, Hasan SK, Lavorgna S, Laterza S, et al. Identification of emerging FLT3 ITD-positive clones during clinical remission and kinetics of disease relapse in acute myeloid leukaemia with mutated nucleophosmin. Brit J Haematol. 2013;161(May):533-40.

35. Voso MT, Larson RA, Jones D, Marcucci G, Prior T, Krauter J, et al. Midostaurin in patients with acute myeloid leukemia and FLT3-TKD mutations: a subanalysis from the RATIFY trial. Blood Adv. 2020;4(Oct):4945-54.

36. Mead AJ, Linch DC, Hills RK, Wheatley K, Burnett AK, Gale RE. FLT3 tyrosine kinase domain mutations are biologically distinct from and have a significantly more favorable prognosis than FLT3 internal tandem duplications in patients with acute myeloid leukemia. Blood. 2007;110(Aug):1262-70.

37. Boddu P, Kantarjian H, Borthakur G, Kadia T, Daver N, Pierce $S$, et al. Co-occurrence of FLT3-TKD and NPM1 mutations defines a highly favorable prognostic AML group. Blood Adv. 2017;1(Aug):1546-50.

38. Bacher U, Haferlach C, Kern W, Haferlach T, Schnittger S. Prognostic relevance of FLT3-TKD mutations in AML: the combination matters-an analysis of 3082 patients. Blood. 2008;111(Mar):2527-37.

39. Whitman SP, Ruppert AS, Radmacher MD, Mrozek K, Paschka P, Langer C, et al. FLT3 D835/I836 mutations are associated with poor disease-free survival and a distinct gene-expression signature among younger adults with de novo cytogenetically normal acute myeloid leukemia lacking FLT3 internal tandem duplications. Blood. 2008;111(Feb):1552-9.

40. Kayser S, Schlenk RF, Londono MC, Breitenbuecher F, Wittke $\mathrm{K}$, Du J, et al. Insertion of FLT3 internal tandem duplication in the tyrosine kinase domain- 1 is associated with resistance to chemotherapy and inferior outcome. Blood. 2009;114 (Sep):2386-92 .

41. Heiblig M, Labussière H, Larcher MV, Fossard G, Balsat M, Ducastelle S, et al. Impact of DNMT3a status on post induction NPM1 MRD predictive value on survival in elderly AML patients treated intensively. Blood. 2020;136:7-8.
42. The Cancer Genome Atlas (TCGA). Genomic and epigenomic landscapes of adult de novo acute myeloid leukemia. N. Engl J Med. 2013;368(May):2059-74.

43. Loghavi S, Zuo Z, Ravandi F, Kantarjian HM, Bueso-Ramos C, Zhang L, et al. Clinical features of de novo acute myeloid leukemia with concurrent DNMT3A, FLT3 and NPM1 mutations. J Hematol Oncol. 2014;7(Oct):74.

44. Bezerra MF, Lima AS, Pique-Borras MR, Silveira DR, CoelhoSilva JL, Pereira-Martins DA, et al. Co-occurrence of DNMT3A, NPM1, FLT3 mutations identifies a subset of acute myeloid leukemia with adverse prognosis. Blood. 2020;135(Mar):870-5.

45. Bisaillon R, Moison C, Thiollier C, Krosl J, Bordeleau ME, Lehnertz B, et al. Genetic characterization of ABT-199 sensitivity in human AML. Leukemia. 2020;34(Jan):63-74.

46. Haferlach C, Mecucci C, Schnittger S, Kohlmann A, Mancini M, Cuneo A, et al. AML with mutated NPM1 carrying a normal or aberrant karyotype show overlapping biologic, pathologic, immunophenotypic, and prognostic features. Blood. 2009;114 (Oct):3024-32.

47. Angenendt L, Rollig C, Montesinos P, Martinez-Cuadron D, Barragan E, Garcia R, et al. Chromosomal abnormalities and prognosis in NPM1-mutated acute myeloid leukemia: a pooled analysis of individual patient data from nine international cohorts. J Clin Oncol. 2019;37(Oct):2632-42.

48. Luskin MR, Huen AO, Brooks SA, Stewart C, Watt CD, Morrissette JJ, et al. NPM1 mutation is associated with leukemia cutis in acute myeloid leukemia with monocytic features. Haematologica. 2015;100(Oct):e412-4.

49. Ganzel C, Manola J, Douer D, Rowe JM, Fernandez HF, Paietta EM, et al. Extramedullary disease in adult acute myeloid leukemia is common but lacks independent significance: analysis of patients in ECOG-ACRIN cancer research group trials, 1980-2008. J Clin Oncol. 2016;34(Oct):3544-53.

50. DiNardo CD, Tiong IS, Quaglieri A, MacRaild S, Loghavi S, Brown FC, et al. Molecular patterns of response and treatment failure after frontline venetoclax combinations in older patients with AML. Blood. 2020;135(Mar):791-803.

51. DiNardo CD, Jonas BA, Pullarkat V, Thirman MJ, Garcia JS, Wei $\mathrm{AH}$, et al. Azacitidine and Venetoclax in previously untreated acute myeloid leukemia. N. Engl J Med. 2020;383 (Aug):617-29.

52. Otoukesh S, Zhang JY, Nakamura R, Stein AS, Forman SJ, Marcucci G, et al. The efficacy of venetoclax and hypomethylating agents in acute myeloid leukemia with extramedullary involvement. Leuk Lymphoma. 2020;61(Jul):2020-3.

53. Pan W, Zhao X, Shi W, Jiang Z, Xiao H. Venetoclax induced complete remission in extramedullary relapse of AML coharboring NPM1, TET2, and NRAS mutations after haploidentical hematopoietic stem cell transplantation. Leuk Lymphoma. 2020;61(Nov):2756-9.

54. NCRI. Recommendations for the management of patients with AML during the COVID19 outbreak: a statement from the NCRI AML Working Party. https://www.rcpath.org/uploads/assets/ d23030b6-7379-4f80-9ed9178c5f864343/Recommendations-forthe-management-of-patients-with-acute-myeloid-leukaemia-AMLduring-the-COVID19-outbreak.pdf. Last accessed 10th February 2021.

55. Zeidan AM, Boddu PC, Patnaik MM, Bewersdorf JP, Stahl M, Rampal RK, et al. Special considerations in the management of adult patients with acute leukaemias and myeloid neoplasms in the COVID-19 era: recommendations from a panel of international experts. Lancet Haematol. 2020;7(Aug):E601-12.

56. Farah N, Burt R, Ibrahim AR, Baker R, Kottaridis PD. Concerns about how to use established minimal residual disease monitoring in the treatment of NPM1-mutant acute myeloid leukaemia (AML) following reduced intensity chemotherapy protocols for 
AML given as a result of the COVID-19 pandemic. Brit $\mathrm{J}$ Haematol. 2020;190(Aug):e208-10.

57. Lachowiez CA, Loghavi S, Kadia TM, Daver N, Borthakur G, Pemmaraju N, et al. Outcomes of older patients with NPM1mutated AML: current treatments and the promise of venetoclaxbased regimens. Blood Adv. 2020;4(Apr):1311-20.

58. Becker H, Marcucci G, Maharry K, Radmacher MD, Mrozek K, Margeson D, et al. Favorable prognostic impact of NPM1 mutations in older patients with cytogenetically normal de novo acute myeloid leukemia and associated gene- and microRNAexpression signatures: a Cancer and Leukemia Group B study. J Clin Oncol. 2010;28(Feb):596-604.

59. Aldoss I, Nakamura R, Yang D, Salhotra A, Stein AS, Pullarkat $\mathrm{V}$, et al. Favorable outcomes for allogeneic hematopoietic cell transplantation in elderly patients with NPM1-mutated and FLT3-ITD-negative acute myeloid leukemia. Bone Marrow Transpl. 2020;55(Feb):473-5.

60. Jentzsch M, Grimm J, Bill M, Goldmann K, Schulz J, Niederwieser D, et al. Outcomes of older patients with NPM1 mutated and FLT3-ITD negative acute myeloid leukemia receiving allogeneic transplantation. Hemasphere. 2020;4(Jan): e326 https://doi.org/10.1097/HS9.0000000000000326

61. Cazzaniga G, Dell'Oro MG, Mecucci C, Giarin E, Masetti R, Rossi V, et al. Nucleophosmin mutations in childhood acute myelogenous leukemia with normal karyotype. Blood. 2005;106 (Aug):1419-22.

62. Warren JT, Link DC. Clonal hematopoiesis and risk for hematologic malignancy. Blood. 2020;136(Oct):1599-605.

63. Falini B, Bolli N, Liso A, Martelli MP, Mannucci R, Pileri S, et al. Altered nucleophosmin transport in acute myeloid leukaemia with mutated NPM1: molecular basis and clinical implications. Leukemia. 2009;23(Oct):1731-43.

64. Schittenhelm MM, Yee KW, Tyner JW, McGreevey L, Haley AD, Town A, et al. FLT3 K663Q is a novel AML-associated oncogenic kinase: determination of biochemical properties and sensitivity to Sunitinib (SU11248). Leukemia. 2006;20 (Nov):2008-14.

65. Jiang J, Paez JG, Lee JC, Bo R, Stone RM, DeAngelo DJ, et al. Identifying and characterizing a novel activating mutation of the FLT3 tyrosine kinase in AML. Blood. 2004;104(Sep):1855-8.

66. Tuval A, Shlush LI. Evolutionary trajectory of leukemic clones and its clinical implications. Haematologica. 2019;104 (May):872-80.

67. Hollink IH, Zwaan CM, Zimmermann M, Arentsen-Peters TC, Pieters R, Cloos J, et al. Favorable prognostic impact of NPM1 gene mutations in childhood acute myeloid leukemia, with emphasis on cytogenetically normal AML. Leukemia. 2009;23 (Feb):262-70.

68. Falini B, Nicoletti I, Martelli MF, Mecucci C. Acute myeloid leukemia carrying cytoplasmic/mutated nucleophosmin (NPMc+ AML): biologic and clinical features. Blood. 2007;109 (Feb):874-85.

69. Mariano AR, Colombo E, Luzi L, Martinelli P, Volorio S, Bernard $\mathrm{L}$, et al. Cytoplasmic localization of NPM in myeloid leukemias is dictated by gain-of-function mutations that create a functional nuclear export signal. Oncogene. 2006;25(Jul):4376-80.

70. Albiero E, Madeo D, Bolli N, Giaretta I, Bona ED, Martelli MF, et al. Identification and functional characterization of a cytoplasmic nucleophosmin leukaemic mutant generated by a novel exon-11 NPM1 mutation. Leukemia. 2007;21(May):1099-103.

71. Martelli MP, Rossi R, Varasano E, Specchia G, Di Raimondo F, Avvisati G, et al. Identification and characterization of novel rare nucleophosmin (NPM1) gene mutations in acute myeloid leukemia (AML) by a combinatorial approach of immunohistochemistry and molecular analyses. Blood. 2016;128:1717.
72. Falini B, Martelli MP, Bolli N, Bonasso R, Ghia E, Pallotta MT, et al. Immunohistochemistry predicts nucleophosmin (NPM) mutations in acute myeloid leukemia. Blood. 2006;108 (Sep):1999-2005.

73. Dillon R, Potter N, Freeman S, Russell N. How we use molecular minimal residual disease (MRD) testing in acute myeloid leukaemia (AML). Brit J Haematol. 2020 (Oct). https://doi.org/10. 1111/bjh.17185. Online ahead of print.

74. Konoplev S, Yin CC, Kornblau SM, Kantarjian HM, Konopleva $\mathrm{M}$, Andreeff M, et al. Molecular characterization of de novo Philadelphia chromosome-positive acute myeloid leukemia. Leuk Lymphoma. 2013;54(Jan):138-44.

75. Kim MJ, Ahn S, Jeong SH, Jang JH, Han JH, Choi JR, et al. Minor BCR-ABL1-Positive acute myeloid leukemia associated with the NPM1 mutation and FLT3 internal tandem duplication. Ann Lab Med. 2016;36(May):263-5.

76. Mariotti B, Meconi F, Palmieri R, De Bellis E, Lavorgna S, Ottone T, et al. Acute myeloid leukemia with concomitant BCRABL and NPM1 mutations. Case Rep Hematol. 2019;2019 (Apr):6707506 https://doi.org/10.1155/2019/6707506.

77. Soupir CP, Vergilio JA, Dal Cin P, Muzikansky A, Kantarjian $\mathrm{H}$, Jones D, et al. Philadelphia chromosome-positive acute myeloid leukemia - a rare aggressive leukemia with clinicopathologic features distinct from chronic myeloid leukemia in myeloid blast crisis. Am J Clin Pathol. 2007;127 (Apr):642-50.

78. Chen W, Konoplev S, Medeiros LJ, Koeppen H, Leventaki V, Vadhan-Raj S, et al. Cuplike nuclei (prominent nuclear invaginations) in acute myeloid leukemia are highly associated with FLT3 internal tandem duplication and NPM1 mutation. Cancer. 2009;115(Dec):5481-9.

79. Carlsen E, Bailey NG, Aggarwal N, Illar GM, Wild M, Yatsenko SA, et al. Clinicopathologic characterization of hypocellular acute myeloid leukemia (AML) showed fewer genetic abnormalities involving cell proliferation and NPM1 when compared with nonhypocellular AML. Am J Clin Pathol. 2021;155 (Feb):446-54.

80. Arana Rosainz MJ, Nguyen N, Wahed A, Lelenwa LC, Aakash $\mathrm{N}$, Schaefer K, et al. Acute myeloid leukemia with mutated NPM1 mimics acute promyelocytic leukemia presentation. Int J Lab Hematol. 2021;43(Apr):218-26.

81. Campregher PV, Pereira WD, Lisboa B, Puga R, Rodrigues ED, Velloso P, et al. A novel mechanism of NPM1 cytoplasmic localization in acute myeloid leukemia: the recurrent gene fusion NPM1-HAUS1. Haematologica. 2016;101(Jul):287-90.

82. Yang F, Anekpuritanang T, Press RD. Clinical utility of nextgeneration sequencing in acute myeloid leukemia. Mol Diagn Ther. 2020;24(Feb):1-13.

83. Schnittger S, Bacher U, Haferlach C, Alpermann T, Dicker F, Sundermann J, et al. Characterization of NPM1-mutated AML with a history of myelodysplastic syndromes or myeloproliferative neoplasms. Leukemia. 2011;25(Apr):615-21.

84. Montalban-Bravo G, Kanagal-Shamanna R, Sasaki K, Patel K, Ganan-Gomez I, Jabbour E, et al. NPM1 mutations define a specific subgroup of MDS and MDS/MPN patients with favorable outcomes with intensive chemotherapy. Blood Adv. 2019;3 (Mar):922-33.

85. Forghieri F, Nasillo V, Paolini A, Bettelli F, Pioli V, Giusti D, et al. NPM1-Mutated myeloid neoplasms with $<20 \%$ blasts: a really distinct clinico-pathologic entity? Int J Mol Sci. 2020;21 (Nov):8975.

86. Vallapureddy R, Lasho TL, Hoversten K, Finke CM, Ketterling $\mathrm{R}$, Hanson C, et al. Nucleophosmin 1 (NPM1) mutations in chronic myelomonocytic leukemia and their prognostic relevance. Am J Hematol. 2017;92(Oct):E614-8. 
87. Peng J, Zuo Z, Fu B, Oki Y, Tang G, Goswami M, et al. Chronic myelomonocytic leukemia with nucleophosmin (NPM1) mutation. Eur J Haematol. 2016;96(Jan):65-71.

88. Xue E, Tresoldi C, Sala E, Crippa A, Mazzi B, Greco R, et al. Longitudinal qPCR monitoring of nucleophosmin 1 mutations after allogeneic hematopoietic stem cell transplantation to predict AML relapse. Bone Marrow Transpl. 2016;51(Mar):466-9.

89. Hollein A, Meggendorfer M, Dicker F, Jeromin S, Nadarajah N, Kern W, et al. NPM1 mutated AML can relapse with wild-type NPM1: persistent clonal hematopoiesis can drive relapse. Blood Adv. 2018;2(Nov):3118-25.

90. Cocciardi S, Dolnik A, Kapp-Schwoerer S, Rucker FG, Lux S, Blatte TJ, et al. Clonal evolution patterns in acute myeloid leukemia with NPM1 mutation. Nat Commun. 2019;10(May):2031 https://doi.org/10.1038/s41467-019-09745-2.

91. Bertoli S, Tavitian S, Berard E, Mansat-De Mas V, Largeaud L, Gadaud N, et al. More than ten percent of relapses occur after five years in AML patients with NPM1 mutation. Leuk Lymphoma. 2020;61(May):1226-9.

92. Thol F, Gabdoulline R, Liebich A, Klement P, Schiller J, Kandziora $\mathrm{C}$, et al. Measurable residual disease monitoring by NGS before allogeneic hematopoietic cell transplantation in AML. Blood. 2018;132(Oct):1703-13.

93. Ritterhouse LL, Parilla M, Zhen CJ, Wurst MN, Puranik R, Henderson CM, et al. Clinical validation and implementation of a measurable residual disease assay for NPM1 in acute myeloid leukemia by error-corrected next-generation sequencing. Mol Diagn Ther. 2019;23(Dec):791-802.

94. Onecha E, Linares M, Rapado I, Ruiz-Heredia Y, MartinezSanchez P, Cedena T, et al. A novel deep targeted sequencing method for minimal residual disease monitoring in acute myeloid leukemia. Haematologica. 2019;104(Feb):288-96.

95. Lesieur A, Thomas X, Nibourel O, Boissel N, Fenwarth L, De Botton S, et al. Minimal residual disease monitoring in acute myeloid leukemia with non-A/B/D-NPM1 mutations by digital polymerase chain reaction: feasibility and clinical use. Haematologica 2020 Dec;Online ahead of print. https://doi.org/10.3324/ haematol.2020.260133.

96. Schlenk RF, Paschka P, Krzykalla J, Weber D, Kapp-Schwoerer $\mathrm{S}$, Gaidzik VI, et al. Gemtuzumab ozogamicin in NPM1-mutated acute myeloid leukemia: early results from the prospective randomized AMLSG 09-09 Phase III study. J Clin Oncol. 2020;38 (Feb):623-32.

97. Lambert J, Pautas C, Terre C, Raffoux E, Turlure P, Caillot D, et al. Gemtuzumab ozogamicin for de novo acute myeloid leukemia: final efficacy and safety updates from the open-label, phase III ALFA-0701 trial. Haematologica. 2019;104(Jan):113-9.

98. Fournier E, Duployez N, Ducourneau B, Raffoux E, Turlure P, Caillot $\mathrm{D}$, et al. Mutational profile and benefit of gemtuzumab ozogamicin in acute myeloid leukemia. Blood. 2020;135 (Feb):542-6.

99. Chua CC, Roberts AW, Reynolds J, Fong CY, Ting SB, Salmon $\mathrm{JM}$, et al. Chemotherapy and venetoclax in elderly acute myeloid leukemia trial (CAVEAT): a phase Ib dose-escalation study of venetoclax combined with modified intensive chemotherapy. J Clin Oncol. 2020;38(Oct):3506-17.

100. Lachowiez C, Konopleva M, Kadia TM, Daver N, Loghavi S, Wang SA, et al. Interim analysis of the Phase $1 \mathrm{~b} / 2$ study of the BCL-2 inhibitor venetoclax in combination with standard intensive AML induction/consolidation therapy with FLAG-IDA in patients with newly diagnosed or relapsed/refractory AML. Blood. 2020;136:18-20.

101. Kadia TM, Borthakur G, Pemmaraju N, Daver N, DiNardo CD, Sasaki K, et al. Phase II study of venetoclax added to cladribine + Low Dose AraC (LDAC) alternating with 5-Azacytidine demonstrates high rates of minimal residual disease (MRD) negative complete remissions (CR) and excellent tolerability in older Patients with newly diagnosed acute myeloid leukemia (AML). Blood. 2020;136:17-19.

102. Kasper S, Breitenbuecher F, Heidel F, Hoffarth S, Markova B, Schuler M, et al. Targeting MCL-1 sensitizes FLT3-ITD-positive leukemias to cytotoxic therapies. Blood Cancer J. 2012;2(Mar): e60.

103. Straube J, Ling VY, Hill GR, Lane SW. The impact of age, NPM1(mut), and FLT3(ITD) allelic ratio in patients with acute myeloid leukemia. Blood. 2018;131(Mar):1148-53.

104. Sakaguchi M, Yamaguchi H, Najima Y, Usuki K, Ueki T, Oh I, et al. Prognostic impact of low allelic ratio FLT3-ITD and NPM1 mutation in acute myeloid leukemia. Blood Adv. 2018;2 (Oct):2744-54.

105. Boddu PC, Kadia TM, Garcia-Manero G, Cortes J, Alfayez M, Borthakur G, et al. Validation of the 2017 European LeukemiaNet classification for acute myeloid leukemia with NPM1 and FLT3-internal tandem duplication genotypes. Cancer. 2019;125(Apr):1091-1100.

106. Dohner K, Thiede C, Jahn N, Panina E, Gambietz A, Larson RA, et al. Impact of NPM1/FLT3-ITD genotypes defined by the 2017 European LeukemiaNet in patients with acute myeloid leukemia. Blood. 2020;135(Jan):371-80.

107. Brunetti L, Gundry MC, Sorcini D, Guzman AG, Huang YH, Ramabadran R, et al. Mutant NPM1 maintains the leukemic state through HOX expression. Cancer Cell. 2018;34(Sep):499-512. e9.

108. Klossowski S, Miao HZ, Kempinska K, Wu T, Purohit T, Kim E, et al. Menin inhibitor MI-3454 induces remission in MLL1rearranged and NPM1-mutated models of leukemia. J Clin Invest. 2020;130(Feb):981-97.

109. Dzama MM, Steiner M, Rausch J, Sasca D, Schonfeld J, Kunz $\mathrm{K}$, et al. Synergistic targeting of FLT3 mutations in AML via combined menin-MLL and FLT3 inhibition. Blood. 2020;136 (Nov):2442-56.

110. Xie G, Ivica NA, Jia B, Li Y, Dong H, Liang Y, et al. CAR-T cells targeting a nucleophosmin neoepitope exhibit potent specific activity in mouse models of acute myeloid leukaemia. Nat Biomed Eng. 2020 (Oct). https://doi.org/10.1038/s41551-02000625-5. Online ahead of print. PMID: 33046866. 